\title{
Diversity of pea (Pisum sativum) accessions based on morphological data for sustainable field pea breeding in Argentina
}

\author{
I. Gatti ${ }^{1}$, M.A. Espósito² ${ }^{2}$ P. Almirón ${ }^{2}$, V.P. Cravero² and E.L. Cointry ${ }^{1}$ \\ ${ }^{1}$ Department of Genetic and Plant Breeding, \\ Rosario National University, Zavalla, Argentina \\ ${ }^{2}$ Consejo Nacional de Investigaciones Científicas y Técnicas, Zavalla, Argentina \\ Corresponding author: I. Gatti \\ E-mail: ileana1111@gmail.com
}

Genet. Mol. Res. 10 (4): 3403-3410 (2011)

Received April 8, 2011

Accepted September 7, 2011

Published October 31, 2011

DOI http://dx.doi.org/10.4238/2011.October.31.8

\begin{abstract}
We characterized 13 accessions of dry peas of different origins from various growing regions in Argentina, based on three replications of 20 plants cultivated in 2009 and 2010 in a greenhouse, with the objective of selecting those with favorable characteristics for use in breeding programs. Significant differences were found for length and width of stipule and pod, length of the internodes and leaflets, plant height, total number of nodes, number of nodes at the first pod, number of days to flowering and to harvest, number of pods and seeds per pod, 100-seed weight and grain diameter, demonstrating a high degree of genetic variability. Phenotypic correlation analysis demonstrated that large pods produced more seeds per pod, but the seed weight decreased. Plants with smaller number of nodes in the first pod were more productive. Estimates of genotypic correlation coefficients indicated a strong inherent association among the different traits. Clustering methods grouped the accessions into five clusters. Cluster 5 included two accessions and showed the highest values for length and width of stipules (4.9 and $4.5 \mathrm{~cm}$, respectively), length
\end{abstract}


of leaflets $(7.43 \mathrm{~cm})$ and days to flowering (122.6), while cluster 3, with one accession, and cluster 4 , with two accessions, showed the highest values for number of seeds per pod (3.78 and 4.39), number of pods per plant (5.33 and 5.70), length of pods $(5.54$ and $5.72 \mathrm{~cm})$, and width of pods (1.21 and $1.20 \mathrm{~cm}$, respectively). We conclude that accessions in clusters 3 and 4 would be useful for crosses with other cultivars in pea breeding programs.

Key words: Genetic variability; Heritability; Principal component analysis; Cluster; Parental selection

\section{INTRODUCTION}

The pea (Pisum sativum L.) is an annual grain legume of the Papillonaceae family originated in Southwest Asia. It is one of the four most important cultivated legumes alongside soybean, groundnut and beans (Husle, 1994). Because of its high protein level (23-33\%) (Cousin et al., 1985) and the increasing demand for protein-rich raw materials for animal feed or intermediary products for human nutrition there is rising interest in this crop as a protein source (Santalla et al., 2001).

As a cool season crop, it contributes to improving the yield and protein content of the succeeding cereal crop in rotation by improving the nitrogen status of the soil (Rowland et al., 1994). It can also be considered an interesting antecessor to soybean in traditional rotation sequences, as double-cropping soybeans following pea have similar yield to fullseason soybeans. In order to be a profitable alternative to wheat, it is important to look after the quality standards of the pea obtained (proper grain diameter, deep green color and less than $5 \%$ bleached seeds) because profound differences in prices and opportunity of sale can determine its productivity.

This species is predominantly self-pollinated, and breeding has therefore usually been focused on the creation of pure lines. Baranger et al. (2004) proposed that frequent use of few parents in breeding programs has led to a low genetic diversity among pea varieties, but Nisar et al. (2011) found a considerable level of variance available to the breeders and proposed that genotypes from different origins can be utilized for genetic improvement without losing genetic diversity in pea. The success of genetic improvement is attributed to the magnitude and nature of variability present for a specific trait and the effectiveness of a breeding program largely depends on the existence of genetic variability, so a diverse genetic background provides desirable allelic variation among parental lines to produce new and valuable combinations (Tar'an et al., 2005).

The aim of the present study was to evaluate the genetic variance between accessions of pea for different traits to select those that can be used in breeding programs.

\section{MATERIAL AND METHODS}

The present study was carried out at the research station of the Faculty of Agricultural Science, Rosario National University, at Zavalla ( $33^{\circ} 1^{\prime} \mathrm{S}$ and $\left.60^{\circ} 53^{\prime} \mathrm{W}\right)$ during 2009 and 2010 to characterize 13 accessions of pea from different origins. The materials were sowed in $5 \mathrm{dm}^{3}$ pots with a substrate mix of sterile soil, peat and perlite (1:1:1) in a randomized block 
design with 3 replications of 20 plants and conducted under greenhouse conditions.

The traits length (LS) and width (WS) of stipule and pod (LP, WP), length of the internodes (LI) and leaflets (LL), plant height (PH), total number of nodes (NN), number of nodes at the first pod (NFP), number of days to flowering (DF) and to harvest (DH) were measured. Number of pods (NP) and seeds per pod (NS), 100-seed weight (100SW) and grain diameter (GD) were measured at the dry seed stage.

Length and width of stipules and pods, length of the internodes and leaflets, and plant height were recorded in centimeters; grain diameter in $\mathrm{mm}$ and 100 -seed weight in $\mathrm{g}$.

An analysis of variance (ANOVA) procedure, a principal component analysis (PCA) and Euclidean distances were calculated. A cluster analysis was carried out on the matrix of Euclidean distances, and a dendrogram using "Ward's minimum variance" was obtained. All the procedures were obtained by the InfoGene software (Balzarini and Di Renzo, 2003).

Genetic correlations between traits were determined according to the method of Know and Torrie (1964): $\mathrm{rg}=$ Covgij/ ( $\left.\sigma 2 \mathrm{gi}{ }^{*} \sigma 2 \mathrm{gj}\right)$ where Covgij, $\sigma 2 \mathrm{gi}$ and $\sigma 2 \mathrm{gj}$ are the estimates of covariance and variance for traits $i$ and $\mathrm{j}$ respectively.

Due to the absence of significant $\mathrm{G} \times \mathrm{E}$ interaction, the analysis of broad-sense heritability was carried out for both years together.

\section{RESULTS AND DISCUSSION}

Average mean values, standard deviations and heritability values for the traits analyzed in the present study are presented in Table 1. Highly significant variation among materials was found in all characters, except for width of pod (WP) where the differences were significant. In recent years, a considerable loss of pea landraces and consequential loss of genetic variability in European countries and other areas has been reported by some authors (Pošvec and Griga, 2000), but other studies have indicated the existence of variation among genotypes for most of the studied traits (Kumar and Jain, 2003;Gupta et al., 2006). The significant differences found in the present study show the existence of genetic variability for the traits analyzed, in concordance with Tihomir (2009) who, working with 18 accessions, found that genetic variability among accessions was high enough to suggest that genetic diversity of pea germplasm is still sufficient for the creation of new favorable gene combinations. We therefore concluded that it is possible to select parental lines among the accessions analyzed in the present study to be used in a breeding program.

Phenotypic and genotypic correlation coefficients between traits are shown in Table 2. Among the vegetative traits, LS showed highly significant phenotypic correlation with WS ( $\mathrm{r}$ $=0.92)$, $\mathrm{LL}(\mathrm{r}=0.58), \mathrm{NN}(\mathrm{r}=0.41)$ and $\mathrm{PH}(\mathrm{r}=0.56)$. LL had highly significant correlations with WS $(r=0.59)$, NN $(r=0.62)$, NFP $(r=0.44)$ and DH $(r=0.43)$; and PH showed highly significant correlations with WS $(\mathrm{r}=0.47)$ and LI $(\mathrm{r}=0.76)$. Among the traits more related to yield, NP and NS showed negative phenotypic correlation with NFP $(r=-0.56$ and $r=-0.63$ respectively). Also, NS was positively correlated with $\mathrm{LP}(\mathrm{r}=0.60)$ and $\mathrm{WP}(\mathrm{r}=0.48)$, but negatively with $100 \mathrm{SW}(\mathrm{r}=-0.42)$, and GD was positively correlated to 100SW $(\mathrm{r}=0.54)$ so, it can be concluded that a large pod size produces more seeds per pod, but these seeds are smaller, so the weight of 100 seeds shows a decrease even though NS didn't show a significant phenotypic correlation with GD $(r=-0.14)$, and that plants with a smaller number of nodes for the first pod are more productive. 
I. Gatti et al.

3406

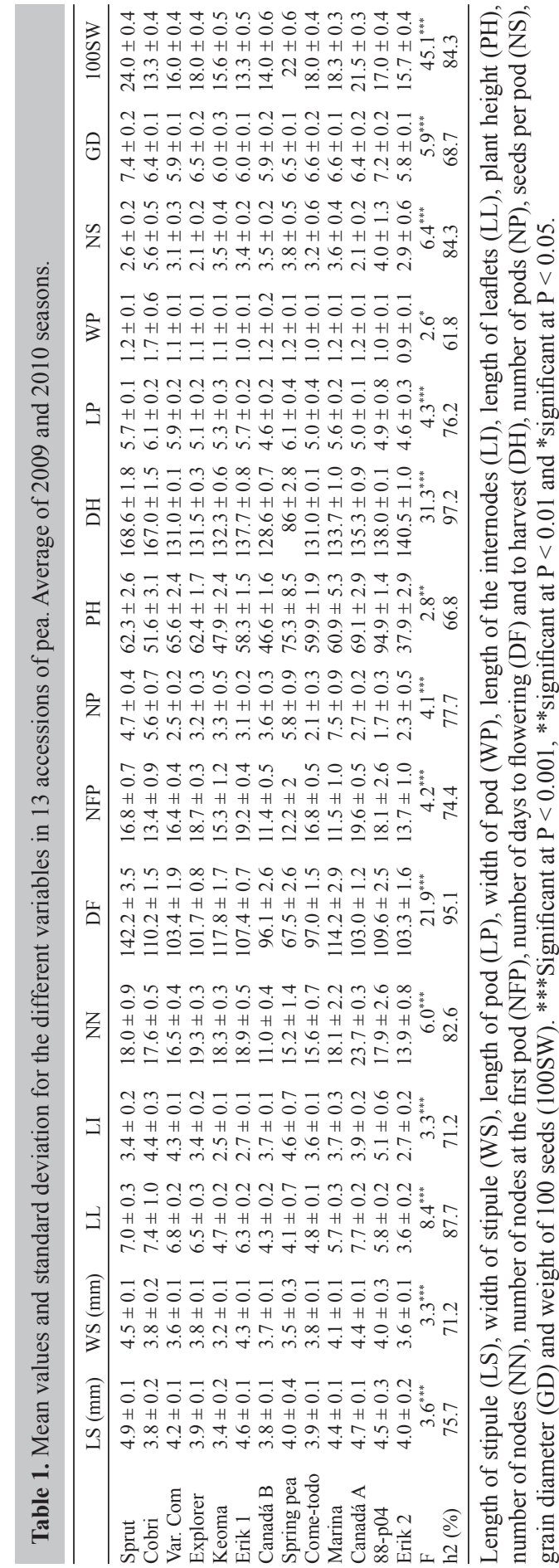

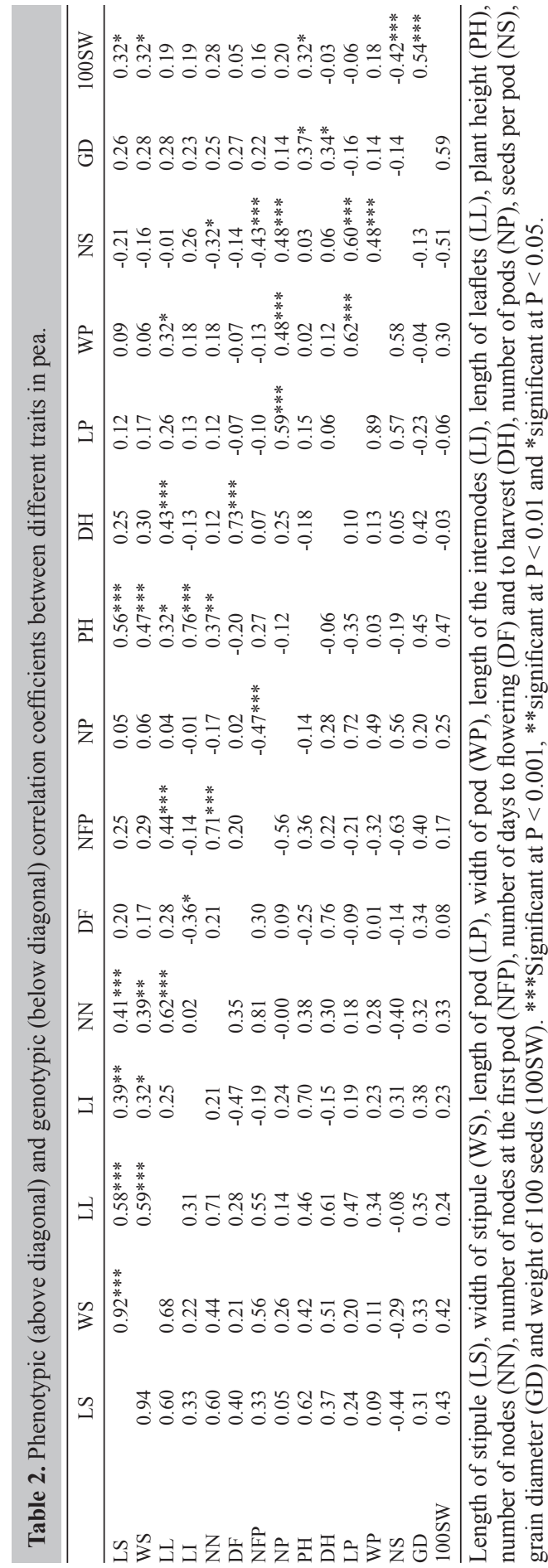

CFUNPEC-RP www.funpecrp.com.br 
As expected, DF showed highly significant correlation with DH, and NN with NFP.

In concordance with Chaudhary and Sharma (2003), Espósito et al. (2009) and Ghobary, (2010), the estimates of genotypic correlation coefficient were, in general, higher than corresponding phenotypic correlation coefficient, which indicates a strong inherent association among different traits under study.

Relationships between the 13 accessions revealed by cluster analyses are presented in Figure 1. All the genotypes where categorized into five clusters using the Euclidean distances for linkage. The clusters were differentiated by DF $(\mathrm{F}=3.9, \mathrm{P}<0.01) \mathrm{NFP}(\mathrm{F}=8.7, \mathrm{P}<0.01)$ DH $(\mathrm{F}=5.5, \mathrm{P}<0.01) \mathrm{NP}(\mathrm{F}=7.1, \mathrm{P}<0.01)$ and NS $(\mathrm{F}=4.5, \mathrm{P}<0.01) \mathrm{WS}(\mathrm{F}=4.98, \mathrm{P}<$ $0.01)$, LL $(\mathrm{F}=7.9, \mathrm{P}<0.01)$, and 100SW $(\mathrm{F}=6.8, \mathrm{P}<0.01)$.

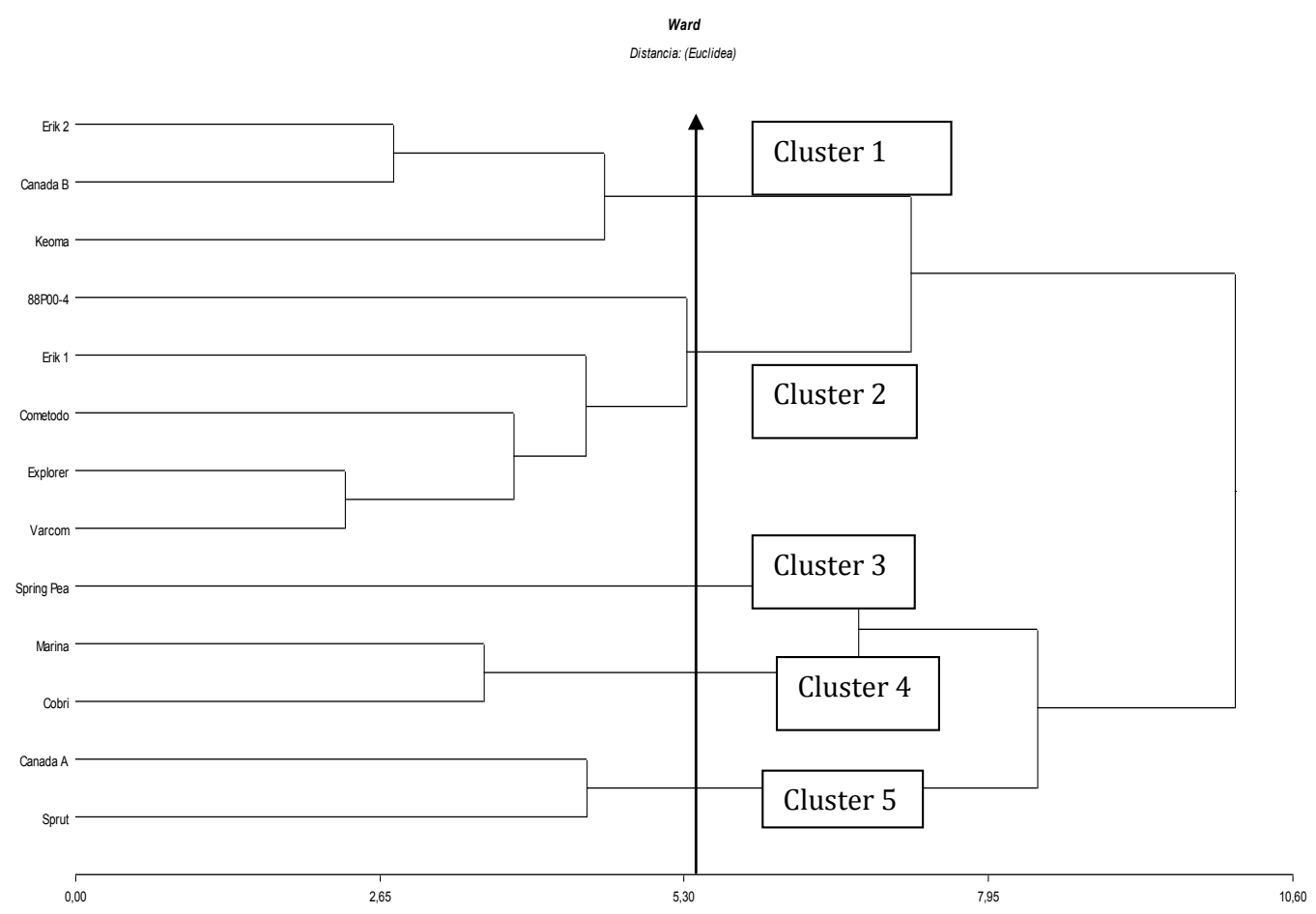

Figure 1. Dendrogram showing the grouping of the 13 accessions of pea.

Cluster I included three accessions and Cluster II included five accessions. Both clusters had intermediate values for all the variables analyzed. Cluster III consisted of only one accession and was characterized by the lowest values for DF, NFP and DH. Cluster IV included two accessions and showed the highest values for DH, NP and NS. Cluster V also included two accessions and showed the highest values for WS, LL, DF and 100SW. Mean values for each cluster are presented in Table 3.

A PCA can determine which of the traits most strongly contributes to the PC and reduce the number of traits analyzed to characterize the material that can be used as parental. 
Table 3. Mean values for five clusters based on 15 traits in pea.

\begin{tabular}{|c|c|c|c|c|c|}
\hline \multirow[b]{2}{*}{ Variable } & \multicolumn{5}{|c|}{ Cluster } \\
\hline & 1 & 2 & 3 & 4 & 5 \\
\hline LS & 3.78 & 4.17 & 4.02 & 4.22 & 4.92 \\
\hline WS & 3.52 & 3.86 & 3.72 & 3.98 & 4.50 \\
\hline LL & 4.18 & 6.04 & 4.78 & 6.49 & 7.43 \\
\hline LI & 3.05 & 3.78 & 5.07 & 4.05 & 3.68 \\
\hline $\mathrm{NN}$ & 14.59 & 17.49 & 14.83 & 17.72 & 20.85 \\
\hline DF & 105.90 & 103.78 & 67.00 & 112.24 & 122.61 \\
\hline NFP & 13.37 & 17.95 & 12.17 & 13.57 & 18.47 \\
\hline NP & 3.35 & 2.75 & 5.33 & 5.70 & 3.92 \\
\hline $\mathrm{PH}$ & 43.54 & 67.07 & 77.42 & 59.19 & 65.97 \\
\hline DH & 123.00 & 132.29 & 86.00 & 162.14 & 151.99 \\
\hline LP & 4.84 & 4.83 & 5.54 & 5.72 & 4.99 \\
\hline WP & 1.06 & 1.00 & 1.21 & 1.20 & 1.14 \\
\hline NS & 3.23 & 2.83 & 3.78 & 4.39 & 2.13 \\
\hline GD & 5.92 & 6.25 & 7.11 & 6.15 & 6.86 \\
\hline 100SW & 15.00 & 16.40 & 22.00 & 16.00 & 22.50 \\
\hline
\end{tabular}

Length of stipule (LS), width of stipule (WS), length of pod (LP), width of pod (WP), length of the internodes (LI), length of leaflets (LL), plant height $(\mathrm{PH})$, number of nodes $(\mathrm{NN})$, number of nodes at the first pod (NFP), number of days to flowering (DF) and to harvest (DH), number of pods (NP), seeds per pod (NS), grain diameter (GD) and weight of 100 seeds $(100 \mathrm{SW})$.

In the PCA, four PCs explained $81 \%$ of the total variation observed (Table 4$)$. The first component $\left(\mathrm{PC}_{1}\right)$ explained $32 \%$ of the variation and was positively related to LS, WS, LL, NFP and 100SW. The second component $\left(\mathrm{PC}_{2}\right)$ explained $23 \%$ of the variation and was positively related to yield contributing traits such as NP, LP, WP and NS. The third component $\left(\mathrm{PC}_{3}\right)$ was positively related to LI, $\mathrm{PH}$ and GD while $\mathrm{DF}$ had a substantially negative weight. The fourth $\left(\mathrm{PC}_{4}\right)$ was negatively related to $\mathrm{NN}$ and positively to $\mathrm{DH}$.

Table 4. Matrix of eigenvalues and eigenvectors of principal components for different traits in pea.

\begin{tabular}{|c|c|c|c|c|}
\hline & \multicolumn{4}{|c|}{ Principal Components (PC) } \\
\hline & PC1 & $\mathrm{PC} 2$ & $\mathrm{PC} 3$ & PC4 \\
\hline \multicolumn{5}{|l|}{ Eigenvalues } \\
\hline Variance & 4.75 & 3.44 & 2.67 & 1.33 \\
\hline$\%$ total contribution & 0.32 & 0.23 & 0.18 & 0.09 \\
\hline$\%$ accumulated & 0.32 & 0.55 & 0.72 & 0.81 \\
\hline \multicolumn{5}{|l|}{ Eigenvectors } \\
\hline LS & 0.39 & -0.04 & -0.03 & 0.13 \\
\hline WS & 0.39 & $-8.3 \mathrm{E}-04$ & -0.08 & 0.16 \\
\hline LL & 0.38 & 0.12 & -0.14 & -0.24 \\
\hline LI & 0.08 & 0.22 & 0.47 & 0.05 \\
\hline NN & 0.35 & -0.05 & -0.11 & -0.42 \\
\hline $\mathrm{DF}$ & 0.22 & -0.05 & -0.37 & 0.35 \\
\hline NFP & 0.32 & -0.30 & -0.03 & -0.32 \\
\hline NP & 0.03 & 0.49 & -0.11 & 0.13 \\
\hline $\mathrm{PH}$ & 0.26 & 0.04 & 0.42 & -0.17 \\
\hline $\mathrm{DH}$ & 0.23 & 0.07 & -0.34 & 0.42 \\
\hline LP & 0.02 & 0.42 & -0.22 & -0.37 \\
\hline WP & 0.09 & 0.49 & -0.06 & -0.12 \\
\hline NS & -0.18 & 0.39 & -0.05 & -0.04 \\
\hline $100 \mathrm{SW}$ & 0.28 & 0.09 & 0.28 & 0.14 \\
\hline GD & 0.20 & 0.14 & 0.41 & 0.33 \\
\hline
\end{tabular}

Length of stipule (LS), width of stipule (WS), length of pod (LP), width of pod (WP), length of the internodes (LI), length of leaflets (LL), plant height (PH), number of nodes (NN), number of nodes at the first pod (NFP), number of days to flowering (DF) and to harvest (DH), number of pods (NP), seeds per pod (NS), grain diameter (GD) and weight of 100 seeds (100SW). 
The first two principal components, which contributed about $55 \%$ of variability, were plotted to categorize the accessions (Figure 2) and to observe the relationship between clusters. Clusters 1 and 3 are on the left half of the graphic, whereas Cluster 5 is on the right half, with the highest value for $\mathrm{PC}_{1}$. Clusters 2 and 4 are present in both halves of the graphic, showing intermediate values for the variables related to PC1, while Cluster 1 and Cluster 3 showed the lowest values. Regarding $\mathrm{PC}_{2}$, Clusters 3 and 4 showed the highest values.

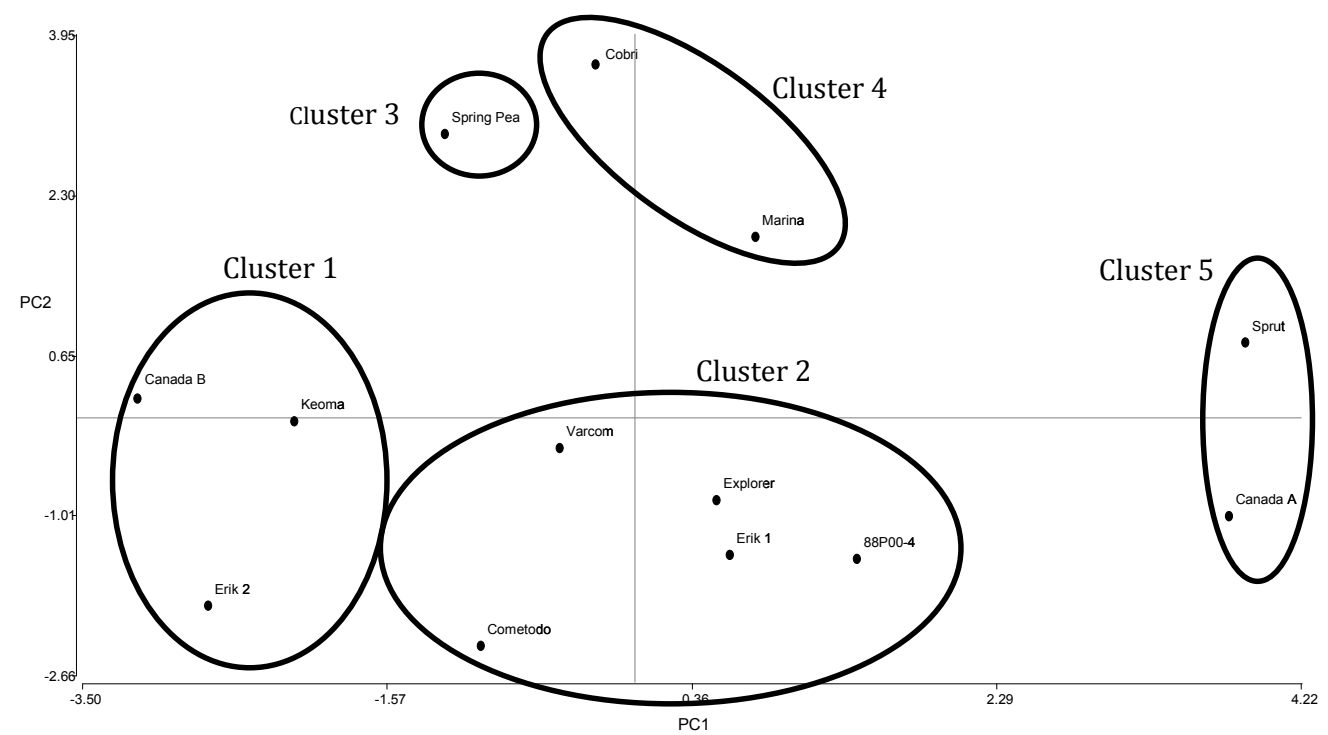

Figure 2. Scatter plot of first two principal components (PC1 and PC2).

Necat et al. (2008) found that number of pods per plant, first pod height and number of seeds per pod and biological yield were the main yield components having maximum direct effects on seed yield and concluded that these could be important for selection criteria in pea breeding. In the present study, number of pods per plant and number of seeds per pod are positively related to $\mathrm{PC}_{2}$ so the accessions from Clusters 3 and 4 may be chosen for hybridization programs with other improved cultivars.

\section{REFERENCES}

Balzarini M and Di Renzo J (2003). Infogen: Software para Análisis Estadísticos de Marcadores Genéticos. Facultad de Ciencias Agropecuarias, Universidad Nacional de Córdoba, Córdoba.

Baranger A, Aubert G, Arnau G, Laine AL, et al. (2004). Genetic diversity within Pisum sativum using protein- and PCRbased markers. Theor. Appl. Genet. 108: 1309-1321.

Chaudhary DK and Sharma RR (2003). Genetic variability, correlation and path analysis for green pod yield and its components in garden pea. Indian J. Hort. 60: 251-256.

Cousin R, Messager A and Vingere A (1985). Breeding for Yield in Combining Peas. In: The Pea Crop. A Basis for Improvement (Hebblethwaite PD, Heath MC and Dawkins TCK, eds.). Butherworkths, London, 115-129.

Espósito MA, Martin EA, Cravero VP, Liberatti D, et al. (2009). Relationships among agronomic traits and seed yield in pea. $B A G$ 20: 01-08. 
Ghobary HMM (2010). Study of relationship between yield and some yield components in garden pea (Pisum sativum L.) by using correlation and path analysis. J. Agric. Res. 36: 351-360.

Hulse JH (1994). Nature, Composition and Utilization of Food Legumes. In: Expanding the Production and Use of Cool Season Food Legumes (Muehlbauer FJ and Kaiser WJ, eds.). Kluwer Academic Publishers, Dordrecht, 77-97.

Know S and Torrie J (1964). Heritability and inter-relationship among traits of two soybean population. Crop Sci. 4: 198.

Necat T, Yesim T, Bunyamin Y and Yusuf D (2008). Relationships between yield and some yield components in pea (Pisum sativum ssp arvense L.) genotypes by using correlation and path analysis. Afr. J. Biotechnol. 7: 4285-4287.

Nisar M, Ghafoor A and Khan MR (2011). Phenotypic variation in the agronomic and morphological traits of Pisum sativum L. germplasm obtained from different parts of the world. Genetika 47: 25-31.

Pošvec Z and Griga M (2000). Utilization of isozyme polymorphism for cultivar identification of 45 commercial peas (Pisum sativum L.). Euphytica 113: 249-256.

Rowland I, Mason M, Pritchard I and French R (1994). Effect of field peas and wheat on the yield and protein content of subsequent wheat crops grown at several rates of applied nitrogen. Aus. J. Expt. Agric. 34: 641-646.

Santalla M, Amurrio JM and De Ron AM (2001). Food and feed potential breeding of green, dry and vegetable pea germplasm. Can. J. Plant Scie. 81: 601-610.

Tar'an B, Zhang C, Warkentin T, Tullu A, et al. (2005). Genetic diversity among varieties and wild species accessions of pea (Pisum sativum L.) based on molecular markers, and morphological and physiological characters. Genome 48: 257-272.

Tihomir C, Tucak M, Popovic S, Bolaric S, et al. (2009). Genetic diversity of pea (Pisum sativum L.) genotypes assessed by pedigree, morphological and molecular data. J. Food Agr. Environ. 7: 343-348. 